\title{
ENREDOS DE CRIAR: PALAVRAS DE ESCRITOR (PORTUGUÊS) SOBRE ARTES DE PINTOR (BRASILEIRO)
}

Dalva Calvão*

e de fato há, como afirma Eduardo Lourenço, por parte da maioria dos portugueses, um amplo desconhecimento sobre a realidade brasileira, em relação à qual é repetido um discurso "pura e simplesmente retórico e onírico", 1 tal não se aplica, certamente, a muitos dos escritores portugueses contemporâneos, que mantêm, ou mantiveram, com a cultura brasileira uma relação de descoberta e de troca, na qual as diferenças puderam ser respeitadas, a partir do entendimento, livre de ressentimentos ou de preconceitos históricos, do inevitável processo de construção do que chamamos uma identidade brasileira. Entre estes escritores podemos incluir José Cardoso Pires, para quem o Brasil parece ter sido, para além de necessário e produtivo refúgio, um lugar de gratificantes encontros.

De suas relações com o Brasil destaca-se o período em que aqui viveu, em 1960, num auto-exílio que o protegeria das ameaças das prisões salazaristas: "Saí porque andavam a prender uma quantidade de escritores. (...) E eu soube que ia ser preso (...). Então vou trabalhar para o Rio (onde sou extraordinariamente

* Universidade Federal Fluminense.

1 LOURENÇO, E. Uma língua, dois discursos. In: LOURENÇO, E. A nau de Ícaro. São Paulo: Cia. das Letras, 2001. p. 149. 
CALVÃO, D. Enrredos de criar: palavras de escritor (português)...

bem recebido), sem nunca dizer que estava fugido." 2 No Rio de Janeiro, ele fica durante alguns meses, como redator do jornal Última Hora e como colaborador da revista Senhor. Possivelmente, aos vínculos estabelecidos nessa época estariam relacionadas algumas das experiências vividas depois, como a vinda ao Rio, em 1971, a convite da Editora Civilização Brasileira, para o lançamento de $O$ Delfim, ou o ensino de Literatura Brasileira, paralelamente ao de Literatura Portuguesa, no King's College da Universidade de Londres, entre 1969 e $1970{ }^{3}$ Não será, portanto, por acaso, que, em entrevista por ocasião do lançamento de Lisboa, Livro de Bordo, em 1997, ao falar de suas relações com as cidades, o escritor destaca a necessidade de se sentir "interrogado" por elas e menciona o Rio de Janeiro como uma das cidades com as quais estabeleceu tal cumplicidade: "Paris, por exemplo, não me interroga. Enquanto que nas cidades de que gosto (Londres, Rio de Janeiro, Barcelona, Praga), sinto-me interrogado. Em toda parte há bocados de mim." 4

Desse Rio que o interrogava, Cardoso Pires revela seu conhecimento, por exemplo, em várias passagens de Alexandra Alpha, que se inicia, justamente, com a queda de um "anjo" de asa-delta "nuns rochedos do litoral conhecido por ponta do Arpoador." 5 Na Fotobiografia organizada por Inês Pedrosa, foi reproduzido o mapa, cuidadosamente desenhado à mão pelo escritor, de toda a orla marítima sobrevoada por aquele anjo, num cuidado de minúcias confirmador da intimidade do autor com a geografia da cidade brasileira. Sobre esse romance vale, aliás, lembrar que ele parece ter merecido da crítica brasileira um reconhecimento maior do que o que lhe foi conferido em seu próprio país: se, em Portugal, ele não recebeu o mesmo acolhimento de outras obras do autor, no Brasil lhe foi concedido o Prêmio da Associação de Críticos de São Paulo, em 1987, o que pode servir de exemplo à via de mão dupla em que se constituíram as relações de Cardoso Pires com o Brasil.

Assim sendo, o diálogo do romancista com as produções de artistas brasileiros, ou as suas referências a nossos escritores, tornam-se, mais que previsíveis, quase que inevitáveis. Dentre esses diálogos, o que, talvez, em primeiro lugar, nos ocorra seja o estabelecido com Carlos Drummond de Andrade, mais especificamente com o verso de que Cardoso Pires se apropria para o

2 PedrosA, I. Entrevista com Cardoso Pires. In: PEDROSA, I. José Cardoso Pires - fotobiografia. Lisboa: Dom Quixote, 1999. p. 56.

3 Cf. PEDROSA, op. cit., p. 74.

4 SILVA, R. da. Entrevista com Cardoso Pires. Jornal de Letras, Artes e Idéias, 19 nov. 1997 (apud PEDROSA, op. cit., p. 124).

5 PIRES, J. C. Alexandra Alpha. São Paulo: Cia. das Letras, 1988. p. 9. 
batismo de seu livro de ensaios -E agora, José? -, repetindo, para o conjunto, o título do último ensaio, no qual, retomando estrofes inteiras do poema drummondiano, expressa sua perplexidade e suas apreensões diante dos novos rumos que se delineiam para o país pós-Revolução dos Cravos.

No entanto, nesse mesmo livro, outro ensaio chama nossa atenção, apontando para o diálogo, aparentemente mais inesperado, estabelecido pelo escritor português com outro artista brasileiro: refiro-me ao texto intitulado "Alguém: no Arco-Íris", em que, num misto de homenagem e de comentário crítico, Cardoso Pires nos fala sobre Cândido Portinari. Sobre esse texto, talvez fosse interessante, em primeiro lugar, ressaltar que, na organização do livro, ele se insere na parte significativamente denominada "Retrato dos outros", na qual o autor relembra, além de Portinari, mais seis artistas, todos tendo em comum com o pintor brasileiro a posição questionadora, a inquietação revolucionária na vida e na arte. Sem se desviar demasiadamente da linguagem exigente e objetiva de seus textos de ficção, mas se permitindo a palavra mais emocionada e pessoal, Cardoso Pires, nesses ensaios, recupera imagens e relata experiências dos portugueses Castro Soromenho, Alves Redol, José Dias Coelho e João Abel Manta (os dois últimos, artistas plásticos); do angolano Luandino Vieira; do italiano Elio Vittorini. Tais escolhas e as reflexões que as acompanham poderiam, na verdade, antes de tudo, servir-nos como indicações sobre questionamentos do próprio escritor, sobre seus próprios posicionamentos existenciais e estéticos.

Parece, pois, que, independentemente de laços afetivos ou, algumas vezes, da necessidade de denunciar esquecimentos e injustiças, a elaboração desses retratos se configura, sobretudo, como um exercício crítico, resultante da positiva avaliação das produções e das existências de seus retratados, de uma possível identificação estabelecida com eles. Tal exercício guarda, certamente, parentesco próximo com o que é levado a efeito pelo escritor em seus textos ficcionais, através de vasta e constante atividade intertextual. Apenas no texto de ficção, a reflexão crítica se confunde com a atividade de criação, enquanto que, no texto ensaístico, ela se apresenta de forma mais direta e, em princípio, desvinculada de compromissos com o resultado estético, embora, muitas vezes, os ensaios de "Retrato dos outros" repitam algumas das marcas que definiram o trabalho literário do autor, apresentando-se como construções que rejeitam uma classificação definitiva. Por outro lado, vale a pena registrar que, para Cardoso Pires, o trabalho crítico se configuraria também como um trabalho de criação, como vemos afirmado em entrevista de 1972: "Quanto a mim, investigar (como 
CALVÃO, D. Enrredos de criar: palavras de escritor (português)...

disse Langevin) e criticar (como escreveu Oscar Wilde) também são formas de criação específica." 6

No texto sobre Portinari, os aspectos apontados se fazem presentes: enquanto crítica, esse texto, como os outros, já se definiria como essa "forma de criação específica" valorizada pelo autor e, ao mesmo tempo, talvez de maneira mais acentuada que em alguns outros, ele exibe a marca poética em sua linguagem supostamente mais referencial, revelando resultados de um trabalho criativo. Entretanto, nele podemos observar, ainda, outra questão relacionada igualmente à convivência entre trabalho crítico e atividade de criação: isso porque, ao comentar aspectos da personalidade do pintor brasileiro, Cardoso Pires dá especial relevo à sua capacidade de refletir e de expor idéias a respeito dos processos artísticos, à sua facilidade de falar sobre os "enredos de criar". 7 Segundo Cardoso Pires, Portinari, igualado nisto a outros grandes pintores (e são mencionados Kandinsky, Dubuffet e Júlio Pomar), possuía uma espécie de "condão" para expor suas reflexões sobre os "ofícios de criar, suas descobertas e suas mentiras" (p. 39). Fascinado pelo que chama de "felicidade da palavra" (p. 40) revelada por pintores quando discorrem sobre a arte, o escritor reflete: "Porquê esse condão?, pergunto-me eu tantas vezes. Porquê esse soletrar engenhoso que caminha do húmus até o fruto e decifra a honesta imagem da criação? E as palavras, quem lhes deu aos pintores esse dizer ao revés do dicionário?” (p. 39).

Enveredando por esse questionamento e propondo uma possível explicação, Cardoso Pires insiste naquilo que se constituiu como uma de suas constantes indagações - a preocupação com os caminhos e mistérios da atividade estética -, revelando, mais uma vez, a lúcida inquietação que atravessou seu percurso e que o situou entre outros escritores do século XX que fizeram dessas indagações o espaço dialético de onde construíram seus textos. Por isso, ultrapassando considerações mais pessoais sobre a vida e a obra do nosso pintor, o ensaio de Cardoso Pires, repetindo o que, com freqüência e de diversificadas maneiras, encontramos em sua ficção, apresenta-se como um texto que fala de modo mais amplo sobre o trabalho de criação, repensando o lugar do artista no mundo.

Nesse sentido, o lugar de Portinari parece ser visto como o valorizado e difícil lugar em que se confundem o privilégio de uma percepção especial sobre a arte e sobre o mundo - aliada a uma incomum determinação para praticá-la-, e

6 NEVES, J. A. da. Entrevista com José Cardoso Pires. O Estado de São Paulo, 23 abr. 1992 (apud PEDROSA, op. cit., p. 96).

7 PIRES, J. C. E agora, José? 2. ed. Lisboa: Dom Quixote, 1999. p. 40. Todas as demais transcrições do livro de Cardoso Pires virão seguidas apenas do número da página. 
as conseqüências resultantes dessa percepção e dessa determinação. Sobre este lugar falam-nos desde logo o título e as primeiras linhas do texto, que nos apresentam o pintor "no arco-íris", "numa cúpula em arco-íris", ao lado de outros pintores, configurando-o, assim, como habitante dessa simbólica e mágica ponte, "caminho e mediação entre a terra e o céu", ${ }^{8}$ como a aludir à capacidade da obra artística de permitir ao homem ultrapassar sua mais terrena condição em direção a atmosferas mais rarefeitas da sensibilidade, vencendo as ameaças que insistem em mantê-lo preso a limitações, paralisado por toda espécie de "ventos" que "uivam" em torno de suas aspirações:

Tal como o vejo, esse alguém está numa cúpula em arco-íris, retratado entre os seus pares. Encontra-se à mão direita de Picasso e quer-me parecer que Rivera the fica ao lado, pele com pele. Ou será Siqueiros? A esta distância é-me impossível distinguir todas a figuras que me constelam a memória. Distingo, sim, um vento, um vento aceso, de largos mundos, a uivar por detrás das escarpas da eternidade e noto que, apesar dele, os rostos dos gloriosos estão impassíveis. Concretamente, o do alguém a que me refiro e que me olha em esplendores de verde e ouro índio, antiquíssimos.

As relações entre Portinari e os pintores mencionados, por evidentes, dispensam comentários. Mais produtivo será relembrarmos as afinidades perceptíveis entre todos eles e o autor do texto, tanto no que diz respeito à experimentação estética, quanto ao que se refere à manutenção de um compromisso de denúncia. A referência a essas afinidades com pintores pode também nos conduzir às ligações mais extensas de Cardoso Pires com a pintura, seu fascínio pelas artes plásticas. Segundo Inês Pedrosa, o escritor "nutria uma verdadeira paixão pela imagem, como atestam os incontáveis textos que escreveu para catálogos de artistas plásticos e os vários livros seus ilustrados por pintores." ${ }^{9} \mathrm{O}$ texto sobre o pintor brasileiro serve de confirmação desse fascínio, enriquecido, no caso, por indisfarçável ligação afetiva, que leva o escritor a desprezar os fatos mais óbvios e superficiais da biografia de Portinari “...qualquer um poderá traçar-lhe o itinerário que começa numa lapa de gente

8 ChEVAlier, J.; GHEERBRANT, A. Dicionário de símbolos. 16. ed. Rio de Janeiro: J. Olympio, 2001. p. 77.

9 PEDROSA, op. cit., p. 13. 
CALVÃO, D. Enrredos de criar: palavras de escritor (português)...

chamada Brodowski, São Paulo, Brasil e que termina no Rio em manhã de sol" (p. 37) - para se concentrar na originalidade de sua arte e na humanidade de sua figura, destacando particularidades que, entre as datas de nascimento e morte "Nascente e foz" (p. 37) - preencheram seu singular percurso, onde "cabe um mundo de mil voltas, europas, américas, amazónias. Um mundo de muita e muitíssima história: café e escravos, conquistadores e pedrarias, pau-ouro, Tiradentes, a fome e o livro" (p. 37). Demonstrando, assim, um adequado conhecimento sobre as experiências vividas ou recriadas pelo pintor, o escritor aponta o caminho para que o texto que compõe seja, não um retrato burocrático, mas uma tentativa de revelação do artista evocado: "E essa será então a verdadeira chave, o registro, quero eu dizer, de uma criatura que cobriu com seu olhar de safira uma imensa geografia de selvas, mulatos e rios arteriais: Brasil"' (p. 37/28).

A partir dessa "chave", que abre a percepção do universo recriado por Cândido Portinari, Cardoso Pires vai resgatando aspectos de sua pessoal e comovida percepção do pintor brasileiro, recompondo conversas e maneiras de ser, mencionando amizades de Portinari, fixando imagens trazidas de encontros passados. Dessas imagens, o pintor emerge como "ave", "ave migradora", "criança envelhecida, surda e coxa", como o "Cândido-Candinho" de muitos amigos, de voz suave e sempre pronto ao diálogo:

Ave? Pronto, seja ave. Quem alguma vez o desencantou no seu atelier no Rio, saltitando de asa quebrada entre vastas paredes, pensaria nisso com certeza. Pensaria nos pássaros órfãos, esses obscuros, que pontilham os terreiros depois da tempestade, e na solidão que os comanda a eles, pássaros. Por cima e nos muros, o arco-da-chuva alastrava em todas as cores com que ele cobria o branco das telas, e a casa era percorrida pelo ciciar - não voz que se ia depenando desse vulto de homem. Portinari falava e falava: de música e de mundo, dos desastres e das alegrias correntes - de poetas, principalmente. (p. 38)

Desses poetas alguns são mencionados no texto - Vinícius de Moraes, Carlos Drummond de Andrade, Mário de Andrade, Guillén e Neruda -, e as referências aos brasileiros (a que se acrescentam referências a Graciliano Ramos e a José Lins do Rego), apenas reafirmam o trânsito do escritor português pelo universo artístico brasileiro, embora essas referências tenham como função visível 
recortar de forma mais nítida o perfil de Portinari, que se completa com as considerações sobre sua outra, menos conhecida e mais esporádica, atividade, a de poeta. De fato, Cardoso Pires faz alusão a essa "outra voz" do pintor, "a das palavras", e transcreve dois poemas cujos manuscritos foram oferecidos a ele pelo próprio pintor, num momento de despedida, no Rio de Janeiro. Em tom em que a evidente ternura ultrapassa de muito a admiração e a reverência, o escritor confessa: "Copio, letra a letra, esta voz de Portinari como quem atravessa uma infância. Passo-a ao papel com a aplicação do escolar: tem a luz do giz sobre a ardósia, o cheiro do cromo, qualquer coisa de recreio" (p. 42).

Possivelmente, bastaria essa citação para evidenciar a compreensão particular que Cardoso Pires teve da maneira de ser de nosso pintor, o lugar de eleição a ele destinado em sua galeria de afetos e, conseqüentemente, a apreensão sutil desenvolvida em relação à arte de Portinari. Não por acaso, deparamo-nos, em diferentes momentos do texto, com referências ao sentido que, fundamentalmente, define a atividade do pintor, o olhar: "cobriu com seu olhar de safira" (p. 37), "carcaça minúscula arrastada por um olhar urgente" (p. 40), "a mão e o olhar secaram nele de golpe" (p. 40), "a olhar o passarinho" (p. 41). O próprio autor se vê incluído no campo de visão de seu retratado: "alguém a quem me refiro e que me olha" (p. 37), indiretamente dando um testemunho da intrínseca e dialética relação estabelecida com o mundo pelo pintor, esse artista que, segundo Merleau-Ponty, por praticar, "uma teoria mágica da visão", "tem que admitir que as coisas entram nele ou que (...) o espírito sai pelos olhos para ir passear pelas coisas, visto que não cessa de ajustar a elas a sua vidência”. ${ }^{10}$

Poderíamos, talvez, dizer que ao próprio Cardoso Pires não faltaram esses olhos privilegiados de pintor: com eles, ele passeou pela vida e pela obra de Portinari, recortando de ambas imagens que melhor lhe reconstruíam o amigo brasileiro. O retrato que, a partir de fragmentos de sua memória, nos é apresentado, está carregado de sua especial vidência da arte do outro. Através desta vidência, as distâncias se desfazem e vestígios de diálogos se corporificam, indiciando estreitas relações e afinidades. As dificuldades apontadas por Eduardo Lourenço nas relações luso-brasileiras inexistiram, ao menos aparentemente, no contato estabelecido entre esses dois artistas. E, embora pudéssemos desejar que as relações entre ambos servissem como uma espécie de caminho ou de modelo para o diálogo entre os dois países, é forçoso reconhecer que tais relações, e a admiração daí advinda, ultrapassaram questões de nacionalidade e de culturas, bem como questões históricas e exigências

10 MERLEAU-PONTY, M. O olho e o espírito. In: DUARTE, R. (Org.). O belo autônomo. Belo Horizonte: UFMG, 1997. p. 264. 
CALVÃO, D. Enrredos de criar: palavras de escritor (português)...

identitárias, fundando-se, principalmente, no universo intemporal e sem fronteiras das afinidades estéticas, este território universal da criação, da indagação e do diálogo.

\title{
RESUMO
}

Ao tecer considerações sobre a obra e a vida de Cândido Portinari, num texto em que admiração e homenagem se confundem com exercício crítico, José Cardoso Pires não apenas desempenha o papel de agente cultural, criando oportunidades de divulgação e de valoração do trabalho artístico, como evidencia o possível diálogo entre as culturas portuguesa e brasileira. Sobre essas questões desenvolvem-se as reflexões deste trabalho.

Palavras-chave: Crítica, criação estética, relações luso-brasileiras.

\begin{abstract}
While making considerations about the work and life of Cândido Portinari, in a text where admiration and homage intertwines with the exercise of criticism, José Cardoso Pires not only plays the role of a culture agent, creating the opportunity to divulge and valorize the artistic work, but also makes evident the dialog between the Portuguese and Brazilian cultures. It is around these two themes that we have developed our work.

Key-words: Criticism, aesthetic creation, Lusitanian-Brazilian relations.
\end{abstract}

\section{REFERENCIAS}

CHEVALIER, J.; GHEERBRANT, A. Dicionário de símbolos. 16. ed. Rio de Janeiro: J. Olympio, 2001.

DUARTE, R. (Org.). O belo autônomo. Belo Horizonte: UFMG, 1997.

LOURENÇO, E. A nau de Ícaro. São Paulo: Cia. das Letras, 2001.

PEDROSA, I. José Cardoso Pires - fotobiografia. Lisboa: Dom Quixote, 1999. 
CALVÃO, D. Enrredos de criar: palavras de escritor (português)...

PIRES, J. C. Alexandra Alpha. São Paulo: Cia. das Letras, 1988.

E agora, José? 2. ed. Lisboa: Dom Quixote, 1999. 